\title{
In-cylinder Studies of Split Injection in a Single Cylinder Optical Diesel Engine
}

M.R. Herfatmanesh, H. Zhao and L. Ganippa

Centre for Advanced Powertrain and Fuels

School of Engineering and Design

Brunel University London

U.K

\begin{abstract}
In order to meet the ever more stringent emission standards, significant efforts have been devoted to the research and development of cleaner IC engines. Diesel combustion and the formation of pollutants are directly influenced by spatial and temporal distribution of the fuel injected. This study investigates the effect of dwell timing on the in-cylinder combustion process and emissions through the application of $70 \% / 30 \%$ split injection strategy in a single cylinder HSDI optical diesel engine. The fuel injection process was illuminated by a high repetition copper vapour laser and recorded synchronously by a high speed video camera. The combustion temperature and soot distribution during the combustion process were measured by a recently developed high speed two-colour system at the authors laboratory. The results indicated that this injection mode has the potential to improve fuel economy and engine performance while substantially reducing the combustion noise, provided that the injection timings are appropriately selected.
\end{abstract}

\section{INTRODUCTION}

Concern over emission of exhaust pollutants has led to the introduction of emission legislations since the 1960s. In order to meet the ever more stringent emission standards, significant efforts have been devoted to the research and development of cleaner Internal Combustion (IC) engines. Diesel combustion and the formation of pollutants are directly influenced by spatial and temporal distribution of the fuel injected. Consequently, numerous research studies have been conducted aimed at more detailed investigation of fuel-air mixing and combustion processes as well as chemical/physical reactions involved in the production of pollutants, in particular Nitrogen Oxides $\left(\mathrm{NO}_{\mathrm{x}}\right)$ and Particulate Matter (PM), the two most perilous emissions produced by diesel engines.

The introduction of the Common Rail (CR) fuel injection system in the 1990s allowed greater control and flexibility on the fuel injection rate, quantity and timing over the entire operating range of diesel engines. The fuel injection pressure is independent of the engine speed; thus, capable of promoting improved fuel evaporation and mixture formation at low speeds and loads. Such control over fuel injection system led to the development of alternative combustion modes including Low Temperature Combustion (LTC) (1), Homogeneous Charge Compression Ignition (HCCI) (2) and Premixed Charged Compression Ignition (PCCI) (3) through the application of different injection strategies. The results revealed the potential for simultaneous reduction of NOx and PM emissions through the application of such combustion modes. The initial investigation on using alternative injection strategies were primarily focused on the application of pilot and main injections or split injections with equal fuel demand per injection (50\%/50\%) (4). The results demonstrated that shorter ignition delay was achieved due to pilot injection, indicating less premixed combustion, lowering the peak heat release rate. Therefore, NOx emission as well as combustion noise was considerably reduced in 
comparison to conventional diesel combustion. In addition, the effect of post injection on further reduction of soot emission was examined by Han et al. (5) and Farrell et al. (6). Their results showed that soot emission was reduced due to improved soot oxidation which was attributed to higher combustion temperature during mixing controlled combustion phase caused by the combustion of fuel injected during post injection. In order to better understand the mixing process, Zhang et al. (7) carried out a series of investigations involving detailed analysis of fuel and air mixing process in a constant volume vessel through the application of Laser Absorption Scattering (LAS). They investigated the mixing process using conventional single injection and compared their results with those obtained through split injection strategies $75 \% / 25 \%, 50 \% / 50 \%$, and $25 \% / 75 \%$. It was reported that the $75 \% / 25 \%$ split injection strategy resulted in maximum soot reduction for the tested engine operating conditions. This was mainly attributed to improved mixing due to increased in-cylinder turbulence caused by the combustion of fuel injected during second injection.

More recently injection strategies have been investigated with up to 4 or 5 injections due to improved capability of modern fuel injection systems. Gill and Zhao (8) investigated the effect of a multiple injection strategy on diesel combustion and emission characteristics using commercially available diesel fuel and bio fuels. HCCI combustion was achieved through the use of multiple injection strategies which resulted in reduction of exhaust emissions. These results were further confirmed through the application of optical diagnostic techniques such as two-colour, chemiluminescence imaging and high speed video imaging. Nevertheless, current understanding of diesel combustion processes and the associated mechanisms of pollutant formation is still limited and requires further investigation in order to meet future emissions legislation. Thus, conventional methods of engine measurement are no longer sufficient for further development of diesel engines. Instead, nonintrusive optical diagnostic techniques have been devised for in-depth analysis of fuel and air mixing. This study investigates the effect of dwell timing on the combustion performance and emissions through the application of $70 \% / 30 \%$ split injection strategy in a single cylinder direct injection optical diesel engine. A Ricardo Hydra single cylinder optical diesel engine was used in which both conventional and optical diagnostic techniques were implemented.

\section{EXPERIMENTAL SETUP}

\subsection{Single Cylinder Optical Engine}

All experimental testing in this study was carried out in a single cylinder Ricardo Hydra engine equipped with a Ford Puma diesel engine cylinder head, designed to be representative of a typical modern High-speed Direct Injection (HSDI) diesel engine. The engine specifications are depicted in Table 1.

The engine consisted of a Ricardo Hydra engine crankcase, extended cylinder block and piston, a standard production cylinder head and common rail fuel injection system. The cylinder head was from a production Ford 2.0 litre ZSD 420 Duratorq turbocharged engine. In this study, a Kistler 6125 piezoelectric pressure transducer was installed in place of the glowplug for in-cylinder pressure measurement and heat release analysis. Optical access was provided by the Bowditch piston design which allowed for the visualisation of the combustion chamber through the axis of the cylinder via a glass window, made from fused silica, mounted in the crown of the piston. An extended piston and cylinder block were required in order to accommodate such optical configuration which consisted of lower and upper parts with a $45^{\circ}$ angled mirror, made of glass with aluminized front surface, between the sections. Therefore, the combustion chamber and cylinder walls can be fully visualised through such optical setup, Figure 1. In addition, the upper cylinder block had three rectangular wall cut-outs which can be fitted with glass 
windows, made of fused silica, for side optical access. Two of these windows were in the same plane allowing laser sheet imaging, Figure 1, while the third window was positioned at $90^{\circ}$, premeditated for imaging and detection purposes.

Table 1 Ricardo Hydra Engine Specifications

\begin{tabular}{ll}
\hline \multicolumn{2}{l}{ Ricardo Hydra Single-Cylinder Engine } \\
\hline Bore & $86 \mathrm{~mm}$ \\
Stroke & $86 \mathrm{~mm}$ \\
Swept Volume & $499 \mathrm{~cm}^{3}$ \\
Compression Ratio & $16: 1$ \\
Piston Bowl Diameter/Depth & $43.4 / 11.6 \mathrm{~mm}$ \\
& Re-entrant bowl with flat bottom \\
Swirl Ratio (Ricardo) & 1.4 \\
Engine Speed for Testing & $1500 \mathrm{rpm}$ \\
\hline
\end{tabular}

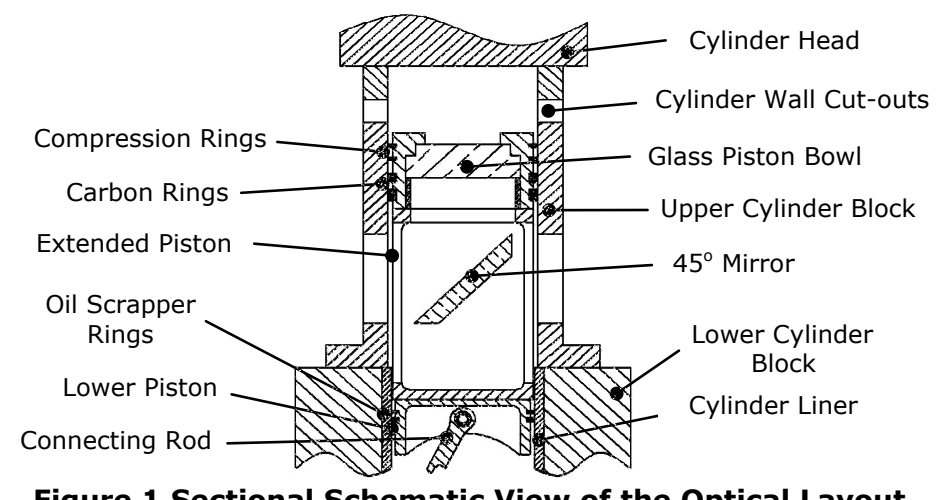

Figure 1 Sectional Schematic View of the Optical Layout

The Fuel Injection Equipment (FIE) consisted of a fuel filter, a $12 \mathrm{~V}$ low pressure pump which drew the filtered fuel from the fuel tank, a first generation Bosch high pressure pump and a Delphi CR fuel injector. The injector utilised in this study was a Delphi multi-hole Valve Covered Orifice (VCO) injector capable of injecting up to 1600 bar. The specifications of the FIE is listed in Table 2.

Table 2 Fuel Injection Equipment Specifications

\begin{tabular}{ll}
\hline Injection System & \\
\hline $1^{\text {st }}$ Generation Common Rail System \\
Maximum Injection Pressure & 1350 bar \\
\hline Delphi Standard Injector & \\
\hline Number of Holes & 6 \\
Hole Size & $0.154 \mathrm{~mm}$ \\
Cone Angle & $154^{\circ}$ \\
Flow Rate & $0.697 \mathrm{I} / \mathrm{min}$ \\
Type & VCO \\
\hline
\end{tabular}

\subsection{Conventional Measurements}

For the injection strategies presented, cylinder pressure data from 20 consecutive engine cycles was recorded from which the heat release rate was calculated. In addition, gaseous exhaust emissions and soot were also measured to assess the effect of the injection strategies on engine performance and emissions. The gaseous exhaust emissions of $\mathrm{CO}, \mathrm{CO} 2, \mathrm{O} 2, \mathrm{uHC}, \mathrm{NO}$ and $\mathrm{NOx}$ were measured by means of a Horiba MEXA-7170DEGR analyser while the soot emissions were measured using an AVL 415 smoke meter. 


\subsection{Injection Rate Measurement}

The fuel injection rate was measured for the tested split injection strategies in order to identify the effect of such injection mode on the fuel injection system. The evaluation method employed in this study was based on Zeuch's method presented by Ishikawa et al. (9). The pressure rise $\Delta \mathrm{P}$ caused by the change in volume $\Delta \mathrm{V}$ due to the fuel injected into the constant volume chamber with volume $V$ can be determined from the following equation,

$\Delta P=k \frac{\Delta V}{V}$

Equation 1

Where $K \quad$ Bulk modulus of fuel

The fuel injection rate can be determined by differentiating Equation 1 with respect to time (t) as depicted below,

$$
\frac{d V}{d t}=\frac{V}{k} \times \frac{d P}{d t}
$$

Equation 2

The area under the fuel injection rate curve represents the quantity of fuel injected.

\subsection{Optical Diagnostic Techniques}

The optical techniques employed in this investigation involved direct fuel spray and combustion visualisation based on high speed imaging technique and flame temperature and soot loading measurements using the two-colour method.

\subsubsection{Direct Combustion Visualisation}

High speed video imaging was employed to record colour video images of fuel spray during the injection period and subsequent combustion process. In order to visualise the fuel spray, a high repetition copper vapour Laser was utilised. The short laser pulse was critical to obtain sharp images of sprays travelling at very high speed. A NAC Memrecam FX6000 high speed colour video camera was used which was equipped with a high speed CMOS sensor. The high speed camera was set to capture videos at 10,000 frames per second (fps), resulting in image resolution of $512 \times 248$ pixels. A Nikon $50 \mathrm{~mm}$ f.1.4 lens was used.

\subsubsection{High-speed Two-colour System}

The two-colour method is a technique capable of estimating the flame temperature and soot concentration within the combustion chamber of diesel engines (10). This technique is based on the principle of flame luminosity. Diesel combustion is rather luminous due to the radiation of soot particles at elevated temperatures. Therefore, the flame temperature and soot concentration in terms of $\mathrm{KL}$ factor can be estimated from the radiation emitted during the combustion process. Plank's law was applied in order to estimate the aforementioned phenomena, Equation 3.

$$
E_{b, \lambda}(T)=\frac{C_{1}}{\lambda^{5}\left[e^{\left(\frac{C_{2}}{\lambda T}\right)}-1\right]}
$$

Equation 3

Where $E_{b, \lambda} \quad$ Monochromatic emission power of a blackbody at temperature T

$T \quad$ Temperature

$C_{1} \quad 1^{\text {st }}$ Plank's constant, $3.7510 \times 10^{-16} \mathrm{Wm}^{2}$

$C_{2} \quad 2^{\text {nd }}$ Plank's constant, $1.4210 \mu \mathrm{mK}$

$\lambda \quad$ Wavelength

However, this equation is based on the radiation of a black body which is a theoretical concept. As a result, the radiation emitted by a blackbody and a non- 
blackbody were linked by introducing the concept of apparent temperature, $T_{a}$, which is defined as the temperature at which the radiation emitted by a blackbody is equal to that of a non-blackbody at a temperature $T$, Equation 4.

$\varepsilon_{\lambda}=\frac{e^{\left(\frac{C_{2}}{\lambda T}\right)}-1}{e^{\left(\frac{C_{2}}{\lambda T_{a}}\right)}-1}$

Equation 4

$\varepsilon_{\lambda}$ is estimated using an empirical correlation developed by Hottel and Broughton (11), Equation 5.

$\varepsilon_{\lambda}=1-e^{\left(\frac{-K L}{\lambda^{\alpha}}\right)}$

Equation 5

Where $K \quad$ Absorption coefficient proportional to soot density

$L \quad$ Geometrical thickness of the flame along the optical axis of the detection system

$\alpha \quad$ Spectral range constant

The product of $\mathrm{K}$ and $\mathrm{L}$ is referred to as the $\mathrm{KL}$ factor which is proportional to soot concentration, Equation 6.

$K L=-\lambda^{\alpha} \ln \left[1-\left(\frac{e^{\left(\frac{C_{2}}{\lambda T}\right)}-1}{e^{\left(\frac{C_{2}}{\lambda T_{a}}\right)}-1}\right)\right]$

Equation 6

The soot radiation was measured at two different wavelengths from which two apparent temperatures were calculated. Based on the measured apparent temperatures, flame temperature and soot concentration were estimated using the calibration data obtained with a tungsten lamp. Although this technique has been used in numerous studies due to the simple experimental and calibration setup, there are several sources of uncertainty or errors such as soot deposition on windows, cylinder wall reflections and inadequate sensitivity of the detection system. Therefore care must be taken when interpreting the results, either qualitatively or quantitatively. These factors may lead to experimental errors of $10 \%(10)$ or even higher depending on the selected wavelengths for measurement. Though, the flame temperature values are less affected (10). Furthermore, most previous two-colour systems were only capable of single shot measurements from different engine cycles, thus suffering from cyclic variations. In order to overcome such difficulty, a high speed two-colour system was developed. The high speed twocolour measurement system consisted of a NAC Memerecam FX6000 high speed camera and a high repetition image intensifier. The optical access through the glass piston was used for this technique. The combustion images were recorded using a standard Nikon $60 \mathrm{~mm}$ f2.8 lens, in front of which, a custom built optical holder was fabricated to house an image doubler and a set of neutral density and bandpass filters at $550 \mathrm{~nm}$ and $750 \mathrm{~nm}$. The neutral density filters were selected such that the intensity of the combustion images was of similar level at the selected wavelengths.

\section{OPERATING CONDITION}

The mechanical and thermal stresses the optical components are exposed to during firing cycles are substantial, thus the operating time of optical engines is extremely limited. As a result, both the coolant and the lubricating oil were heated prior to use 
to ensure reasonable engine temperature was achieved. Thus, problems associated with the cold start were eliminated. In this study $70 \% / 30 \%$ split injection strategy with variable dwell angle was studied under part load operating conditions at the engine speed of $1500 \mathrm{rpm}$, Table 3.

Table 3 Test Conditions

\begin{tabular}{ll}
\hline Intake Air & $\begin{array}{l}100^{\circ} \mathrm{C} \\
\text { Naturally Aspirated, } \approx 0 \text { bar Gauge }\end{array}$ \\
\hline Engine Speed & $1500 \mathrm{rpm}$ \\
\hline Fuel & Commercially Available 49.1 CN Diesel \\
\hline Fuelling Demand & $20 \mathrm{~mm}^{3} /$ cycle \\
\hline Load & $\approx 72 \%$ of full load \\
\hline Injection Pressure & 1200 bar \\
\hline Piston Bowl & $\begin{array}{l}\text { Glass - Pressure, High Speed Imaging, 2-Colour Technique } \\
\text { Metal - Soot, Emissions }\end{array}$ \\
\hline
\end{tabular}

The split Injection strategies were selected such that the injection timing of the second injection remained constant while the injection timing of the first injection was varied. These particular timings were selected amongst a selection of injection timings based on the IMEP values obtained for these strategies. In order to allow comparative analysis of the results, single injection strategies were also performed, serving as the benchmark. The tested strategies are detailed in Table 4.

Table 4 Injection Strategies

\begin{tabular}{|c|c|c|c|c|}
\hline Strategy & Test No & \multicolumn{2}{|c|}{ SOI ( ${ }^{\circ} \mathrm{CA}$ ATDC) } & Dwell Angle \\
\hline \multirow{4}{*}{$\begin{array}{l}\text { Single } \\
\text { Injection }\end{array}$} & A1 & & & \multirow{4}{*}{ N/A } \\
\hline & A2 & & & \\
\hline & A3 & & & \\
\hline & A4 & & & \\
\hline \multirow{5}{*}{$\begin{array}{l}\text { Split } \\
\text { Injection } \\
70 \% / 30 \%\end{array}$} & & $\begin{array}{c}1^{\text {st }} \\
\text { Injection }\end{array}$ & $\begin{array}{c}2^{\text {nd }} \\
\text { Injection }\end{array}$ & \multirow{5}{*}{ Variable } \\
\hline & F1 & -20 & TDC & \\
\hline & F2 & -15 & TDC & \\
\hline & F3 & -10 & TDC & \\
\hline & F4 & -5 & TDC & \\
\hline
\end{tabular}

\section{RESULTS AND DISCUSSION}

\subsection{Effect of Dwell Angle on Fuel Injection Quantity}

The injection rate profiles for the tested split injection strategies were measured using the Zeuch's method described above and are presented in Figure 2. In the case of 10,15 and $20^{\circ} \mathrm{CA}$ dwell timings, the injection quantity of the first injection remained almost constant, though the quantity of the second injection varied depending on the dwell timing used. The result for F4 strategy indicated that $5^{\circ} \mathrm{CA}$ dwell timing was not sufficient for the injector to fully close prior to the onset of the second injection, thus almost replicating a single injection. This resulted in the total injected fuel quantity of approximately $27 \mathrm{~mm}^{3}$ which was substantially higher than the desired quantity of $20 \mathrm{~mm}^{3}$. These considerable variations in the total fuel quantity injected were mainly attributed to the design limitations of the injector utilised as well as the adverse effect of pressure waves in the high pressure fuel line connecting the injector to the common rail, caused by the first injection. The 
effects of such inconsistency in fuel delivery on the combustion and emission characteristics were investigated.

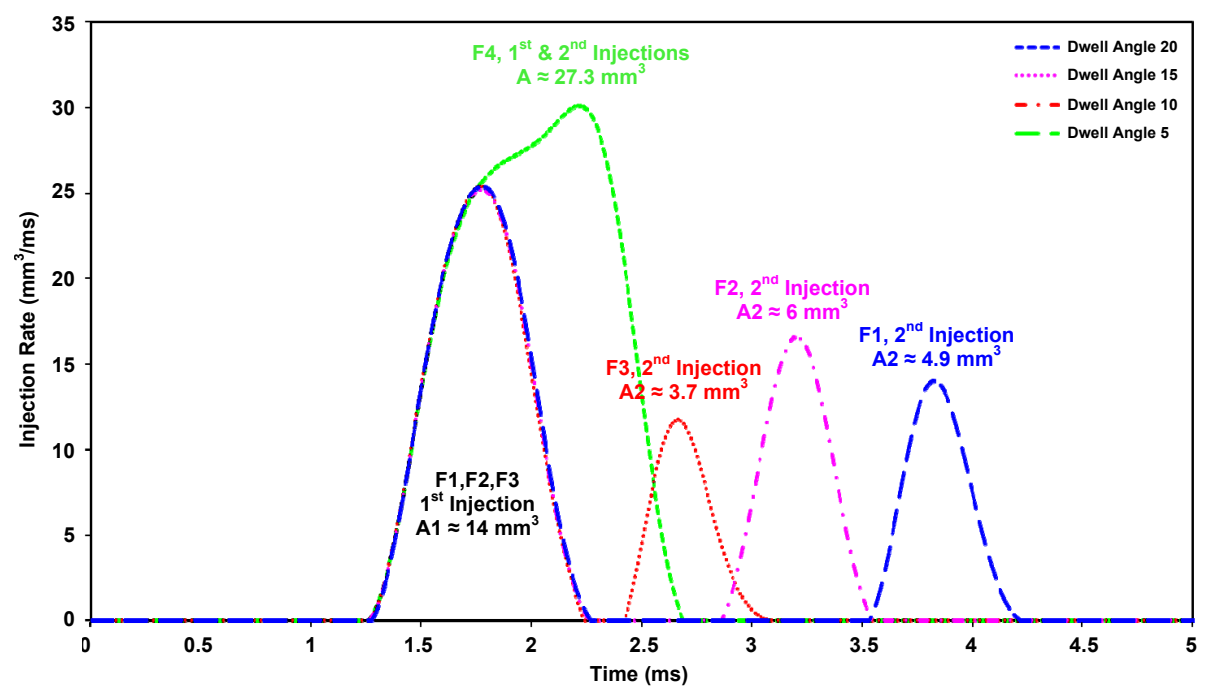

Figure 2 Injection Rate Profiles for Split Injection Strategies

\subsection{Effect of Dwell Angle on Combustion and Emissions}

The in-cylinder pressure and heat release rate data for the split injection strategies are depicted in Figure 3. The peak in-cylinder pressure increased as the first injection timing was further retarded. Although improved fuel evaporation was expected closer to TDC, the trend observed was mainly attributed to the inconsistency in the total injected fuel quantity as illustrated in Figure 2.

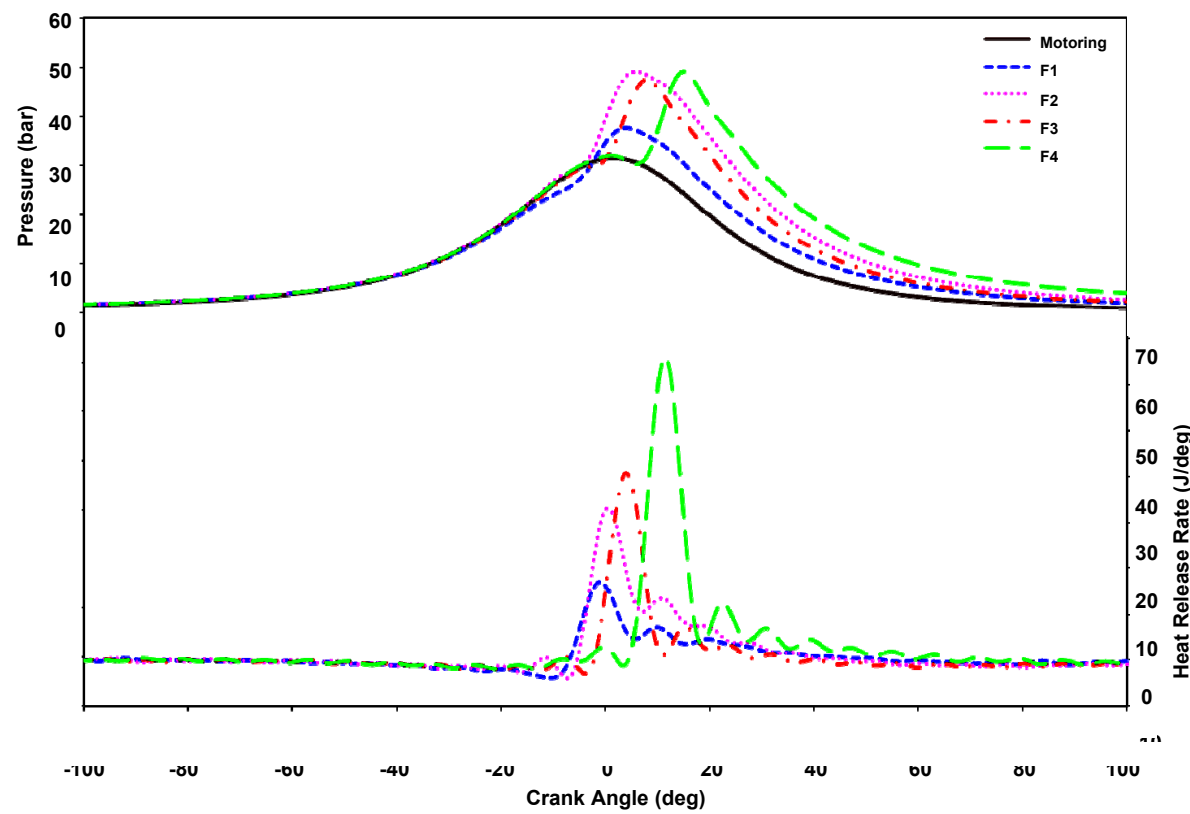

Figure 3 In-cylinder Pressure and Heat Release Rate for Split Injection Strategies 
The heat release rate curves exhibited a drop due to charge cooling effect shortly after the onset of the first injection. Subsequently, the rate of heat release rapidly increased due to the premixed combustion. The peak heat release rate increased as the timing of the first injection was further retarded, this was mainly due to improved fuel evaporation and mixing processes with the exception of F4 strategy whereby the greater fuel quantity injected was the primary factor. However, the reverse was observed during mixing controlled combustion phase, this was attributed to the limited time available for the combustion process to complete.

F2 strategy was selected for further analysis using optical diagnostic techniques since the desired fuel quantity was injected for this strategy. The high speed image sequence for F2 strategy is presented in Figure 4. The first four frames show the fuel spray jets development from the start to the end of the first injection where in the last frame, fuel sprays were almost fully evaporated. The fuel spray impingement on the piston bowl wall was evident in frames three and four where the tip of fuel sprays spread along the piston wall upon impact, generating a mushroom type structure. The frames presented at TDC, $0.9^{\circ} \mathrm{CA}$ ATDC, $1.8^{\circ} \mathrm{CA}$ ATDC and $3.6^{\circ} \mathrm{CA}$ ATDC show the image sequences from the start to the end of the second injection.
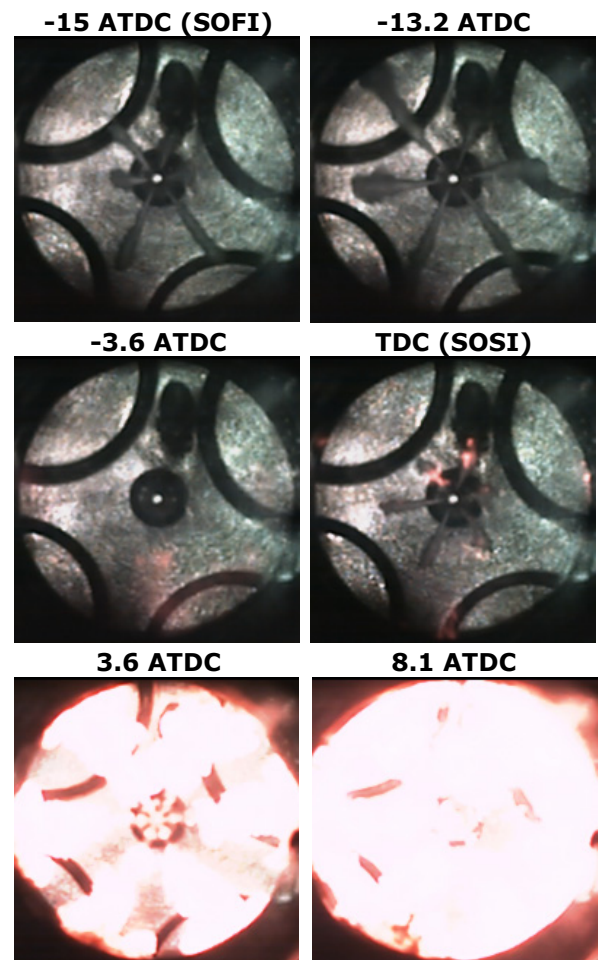

8.1 ATDC
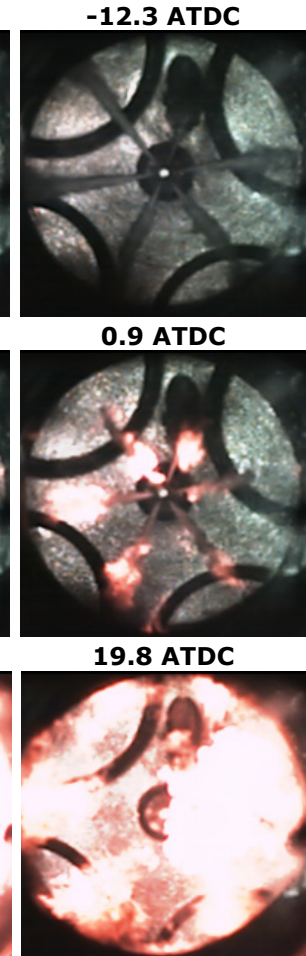

0.9 ATDC

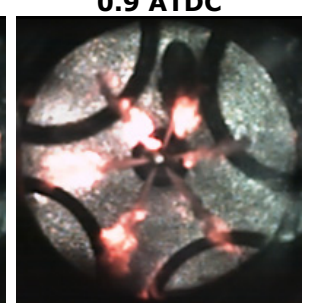

19.8 ATDC
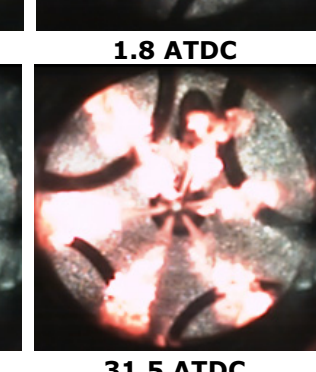

Figure 4 Combustion Image Sequence for F2 Strategy

The first combustion phase which was apparent from the heat release rate data at $6.8^{\circ}$ CA ATDC, Figure 3, resulted in no visible combustion until $-3.6^{\circ}$ CA ATDC where the first visible combustion was observed. The flame was propagated at the tip of the fuel sprays where the fuel vapour was highly concentrated, spreading along the periphery of the fuel sprays where the fuel evaporation rate was considerably higher as shown in frames seven and eight. In the next frame at $3.6^{\circ}$ CA ATDC, the flame at the tip of the sprays spread outwards, following the 
mushroom like structure previously created due to fuel spray impingement. In the subsequent frame at $8.1^{\circ}$ CA ATDC, the flame was fully propagated covering the entire combustion chamber. From the image sequences at $19.8^{\circ}$ CA ATDC and $31.5^{\circ}$ CA ATDC, it was evident that the flame intensity was diminishing during the expansion stroke and moving clockwise due to the swirl motion.

The flame temperature and $\mathrm{KL}$ factor image sequences for the $\mathrm{F} 2$ strategy are shown in Figure 5. Minor combustion at relatively low temperature was detected in the first frame at $0.9^{\circ} \mathrm{CA}$ ATDC, which was in good agreement with the high speed image taken at this crank angle. The subsequent frames at $1.8^{\circ} \mathrm{CA}$ ATDC and $3.6^{\circ}$ CA ATDC showed flame propagation around the tip and periphery of the sprays where high concentration of premixed fuel vapour and air were present. As the combustion developed, the flame temperature and soot formation increased until $8.1^{\circ}$ CA ATDC, due to premixed combustion. Subsequently, the flame temperature and soot concentration steadily decreased during the expansion stroke. Although a luminous flame was detected in high speed images at crank angles later in the expansion stroke, no information could be detected at these crank angles due to inadequate sensitivity of the detection system at the selected wavelengths.
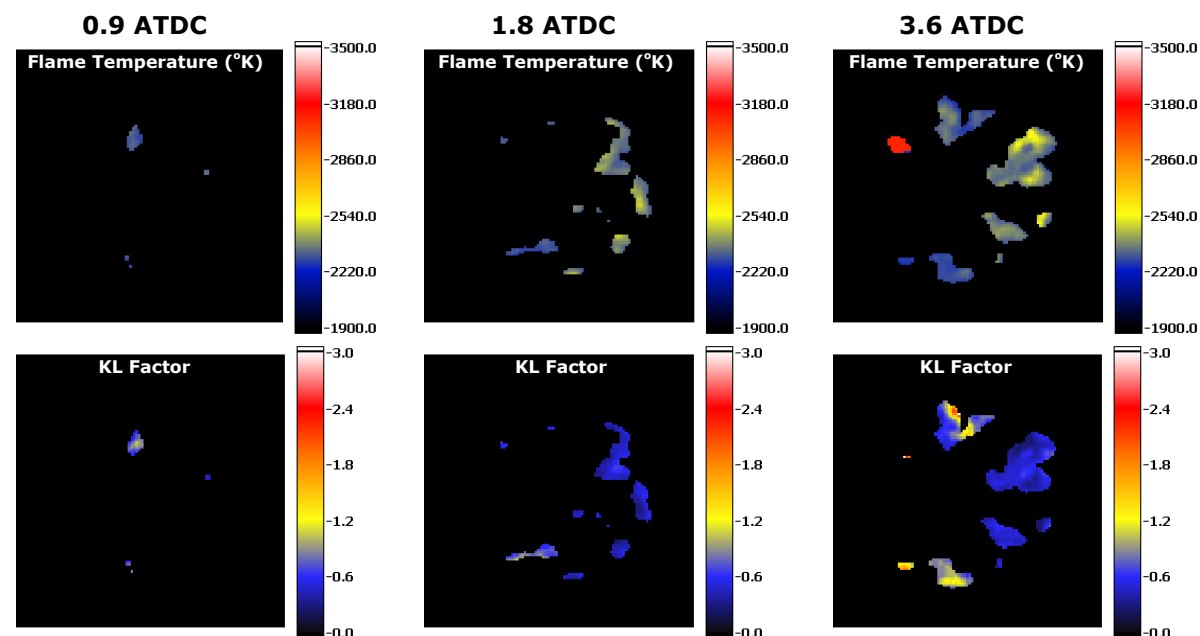

8.1 ATDC

19.8 ATDC
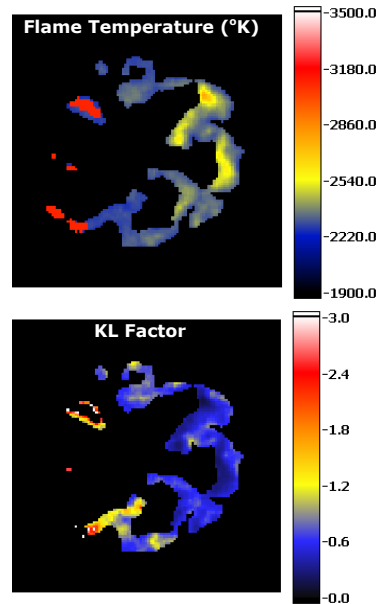
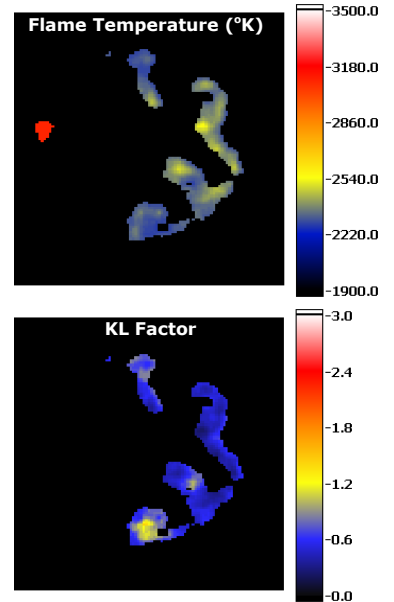

31.5 ATDC
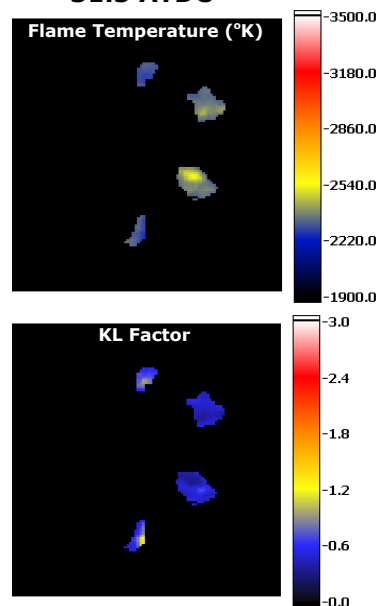

Figure 5 Flame Temperature and KL Factor Images for F2 Strategy 


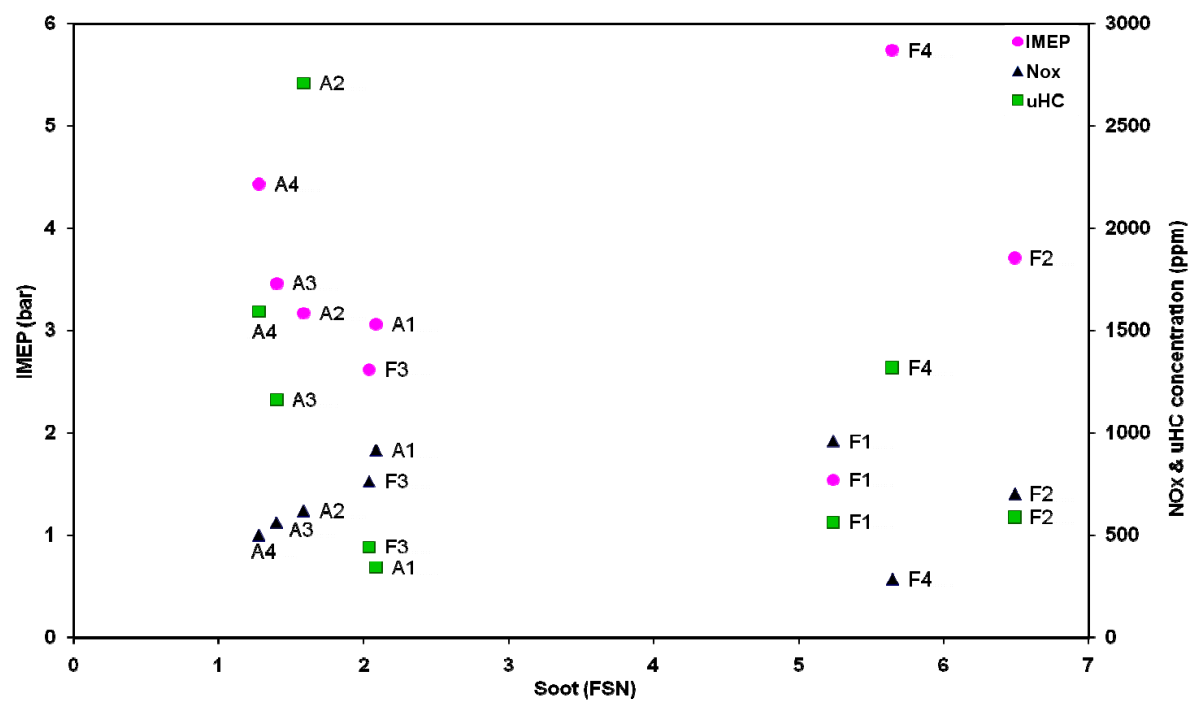

Figure 6 Engine Output and Emissions Values for Split Injection Strategies

The IMEP, soot, Nox and uHC emissions results are depicted in Figure 6 . The substantial variations in the engine output and exhaust emissions for the investigated split injection strategies were primarily caused by the inconsistency in the total fuel quantity injected. However, F2 and A3 strategies can be compared since the total fuel quantity injected was almost identical. In comparison, F2 strategy resulted in higher IMEP values with considerably lower uHC, indicating improved fuel evaporation and mixing processes with significantly lower combustion noise. Nevertheless, this injection strategy led to considerably higher soot and NOX emissions. The former was mainly attributed to the injection of fuel sprays into burning regions during the second injection, resulting in the propagation of highly luminous flame within the combustion chamber as evident in Figure 4 while the latter was due to relatively higher in-cylinder temperature.

\section{CONCLUSIONS}

The following conclusions can be reached from this investigation regarding the tested split injection strategies with variable dwell angle at 1200 bar injection pressure and the engine speed of $1500 \mathrm{rpm}$.

The effect of dwell timing on the performance of the fuel injection system was investigated through the application of the selected injection strategies. The results indicated that careful characterisation of the FIE was essential when applying advanced fuel injection modes. The results from the single and split injection strategies with similar total injected fuel quantity were compared, indicating the possibility of simultaneous improvement of engine performance and reduction of combustion noise. However, the tested split injection strategies resulted in higher soot emissions and almost similar NOx emissions. These pollutants can be reduced to the acceptable limits, Euro V, through the use of diesel particulate filter, NOx trap and EGR systems. Nevertheless, in order to identify the true effects of split injection with variable dwell timing on diesel combustion and emissions further detailed characterisation of the fuel injection system is required. In addition, an explicit conclusion on the advantages of split injection in comparison to that of conventional single injection can only be drawn provided that the effects of such phenomenon under various engine operating conditions are thoroughly assessed. 


\section{REFERENCE LIST}

1. Alriksson, M., Denbratt, I., 2006. Low Temperature Combustion in a Heavy Duty Diesel Engine Using High Levels of EGR. SAE Paper 2006-01-0075

2. Aceves, S.M., Flowers, D.L., Martinez-Frias, J., Smith, J.R., Dibble, R., Au, M., Girard, J., 2001. HCCI Combustion: Analysis and Experiments. SAE Paper 2001-01-2077

3. Nevin, R.M., Sun, Y., Gonzalez, M.A., Reitz, R.D., 2007. PCCI Investigation Using Variable Intake Valve Closing in a Heavy Duty Diesel Engine. SAE Paper 2007-01-0903

4. Nehmer, D., Reitz, R., 1994. Measurement of the Effect of Injection Rate and Split Injections on Diesel Engine Soot and NOx Emissions. SAE Paper 940668

5. Han, Z., Uludogan, A.N., Hampson, G.J., Reitz, R.D., 1996. Mechanism of Soot and NOx Emission Reduction Using Multiple-Injection in a Diesel Engine. SAE Paper 960633

6. Farrell, P.V., Chang, C.T., Su, T.F., 1996. High Pressure Multiple Injection Spray Characteristics. SAE Paper 960860

7. Zhang, Y., Ito, T., Nishida, K., 2001. Characterization of Mixture Formation in Split-Injection Diesel Sprays via Laser Absorption-Scattering (LAS) Technique. SAE Paper 2001-01-3498

8. Gill, K., Zhao, H., 2008. In-cylinder Studies of Fuel Injection and Combustion from a Narrow Cone Fuel Injector in a High Speed Single Cylinder Optical Engine. SAE Paper 2008-01-1789

9. Ishikawa, S., Ohmori, Y., Fukushima, S., Suzuki, T., Takamura, A., Kamimoto, T., 2000. Measurement of Rate of Multiple-Injection in CDI Diesel Engines. SAE Paper 2000-01-1257

10. Zhao, H., Ladommatos, N., 2001. Engine Combustion Instrumentation and Diagnostics. Society of Automotive Engineers, Inc.

11. Hottel, H.G., Broughton, F.P., 1932. Determination of true temperature and total radiation from luminous gas flames. Ind. and Engng Chem., Vol. 4, No. 2, PP 166-175 